\title{
Utility of DNA-Specific Stains in the Assessment of Apoptosis in Oral Exfoliated Buccal Cells of Tobacco Chewers and Patients with Oral Squamous Cell Carcinoma
}

\author{
Priya Shirish Joshi ${ }^{1}$, Dipak Baliram Patil2 ${ }^{2}$, Madhuri S. Chougule ${ }^{3}$, \\ Mahesh P. Dudhanakar4, Bhagyalaxmi P. Hongal ${ }^{5}$, Neha S. Agnihotri ${ }^{6}$
}

1, 3, 4,5,6 Department of Oral Pathology, Vasantdada Patil Dental College and Hospital, Sangli, Maharashtra, India. ${ }^{2}$ Department of Dentistry, Walawalkar Rural Medical College and Hospital, Dervan, Chiplun, Maharashtra, India.

\section{ABSTRACT}

\section{BACKGROUND}

Oral Squamous Cell Carcinoma (OSCC) is a significant medical issue in the Indian subcontinent and is among the top three malignancies in the nation. Oral squamous cell carcinogenesis consists of multiple genetic events and modifications. The genetic modifications seen in head and neck malignant growth are fundamentally because of oncogene actuation and tumour silencer genes inactivation. This causes uncontrolled cell multiplication. Avoidance of apoptosis is one of the signs of human tumours. We wanted to evaluate apoptosis in exfoliated cells harvested from the surface of lesional tissue in patients with OSCC and compare the efficacy and precision of Feulgen stain and 4', 6-Diamidino-2-phenylindole (DAPI) in the assessment of apoptosis as fluorescent marker.

\section{METHODS}

The study was conducted among 60 subjects. The study group (A) consisted of 20 patients with OSCC, group (B) consisted of 20 patients having history of tobacco consumption and the control group consisted of 20 individuals. Oral exfoliated cells were obtained, and 2 slides were prepared from each subject, stained with Feulgen and DAPI stain.

\section{RESULTS}

Frequency of apoptosis was found to be 207 in the control group, 146 in the study group (B) and 120 in study group (A) (OSCC). Mean frequency of apoptosis varied from 10.4 in control group to 7.3 in study group (B) and 6 in study group (A) (OSCC). It was found to be significantly decreasing from control group to study group (B) to study group (A) (OSCC) and this difference is highly significant statistically ( $\mathrm{p}=$ 0.0000 ). We also found fluorescent DAPI to be sensitive compared to Feulgen staining as it limits the incidence of false positives and ultimately gives more precise assessment of DNA damage events.

\section{CONCLUSIONS}

Oral cancer is associated with an impaired apoptosis in the exfoliated buccal cells. Degenerative nuclear alteration suggestive of apoptosis can be a useful tool for early screening and serial monitoring of oral cancer patients. Chromosomal assessment using Fluorescent DAPI is cost effective and perhaps the best approach for screening of OSCC.

\section{KEY WORDS}

Squamous Cell Carcinoma, Apoptosis, Cytology, Fluorescent Probes
Corresponding Author: Dr. Dipak Baliram Patil, Amarjah 5, Residential Complex, BKL walawalkar Rural Medical College and Hospital, Sawarde, Chiplun - 41560, Maharashtra, India.

E-mail: dipak123patil@gmail.com

DOI: $10.14260 /$ jemds/2020/737

How to Cite This Article: Joshi PS, Patil DB, Chougule MS, et al. Utility of DNA-specific stains in the assessment of apoptosis in oral exfoliated buccal cells of tobacco chewers and patients with oral squamous cell carcinoma. J Evolution Med Dent Sci 2020;9(45):3351-3355, DOI: $10.14260 /$ jemds/2020/737

Submission 29-07-2020,

Peer Review 26-09-2020,

Acceptance 03-10-2020,

Published 09-11-2020.

Copyright (C) 2020 Priya Shirish Joshi et al. This is an open access article distributed under Creative Commons Attribution License [Attribution 4.0 International (CC BY 4.0)] 


\section{BACKGROUND}

Globally, oral cancer has the highest incidence among the ten types of malignant neoplasms and is extremely common in developing countries. ${ }^{1}$ Oral malignancy is a significant medical issue in the Indian subcontinent, where its position tops among the three malignancy in the country. ${ }^{2}$ Cancer initiates through numerous stages, each is specified by the genetic imperfections, trailed by clonal extension. The genetic changes seen in head and neck disease are fundamentally because of oncogene actuation just as tumour silencer gene inactivation. These occasions prompt uncontrolled cell multiplication and cell death mechanism i.e. apoptosis. ${ }^{3}$ Avoidance of apoptosis is one of the hallmarks of human diseases that leads in tumour formation and progression. Avoidance of apoptosis can lead to tumour development and progression because tissue homeostasis is the aftereffect of a loss of congruity between cell multiplication and cell death. ${ }^{4}$

Early identification and intervention of potentially malignant lesions promises to improve the survival and limiting co-morbidity of patients. Exfoliative cytology is a straightforward, a traumatic diagnostic procedure which could play an important role in early diagnosis of potentially malignant lesion. Quantitative variable like morphometry is objective, duplicable and salient in cytological assessment in these lesions. ${ }^{5}$ Cytobrush sampling is more commonly utilized these days for exfoliative cytology. It augments the quantity of cells harvest, and encourages their uniform dissemination onto the glass slide, in this way likely improving sensitivity. In micronucleus and chromosomal damage assay, numerous past investigations have indicated false positive outcomes in frequency of micronucleus and apoptosis by utilizing Romanowsky type stains. This eventually results in wrong interpretation of data. Studies have indicated that, compared to nonspecific dyes the sensitivity of DNA specific dyes is practically two-fold. ${ }^{6}$ DNA specific stains like Feulgen, DAPI, acridine orange, acriflavine are easily available, cost effective though technique sensitive.

Hence, we designed a study to evaluate and compare the diagnostic efficacy of Feulgen and DAPI staining in detecting and evaluating apoptosis in exfoliative cytological smears of patients having history of tobacco consumption in any forms and patients with clinically suspected lesions of OSCC.

Deformities in programmed cell death (apoptosis) is responsible for fundamental act in tumour pathogenesis, allowing neoplastic cells to endure expanded life expectancies. As the tumour mass grows, the defect additionally destabilizing the requirement for exogenous survival factors and giving shield from oxidative damage and hypoxia. ${ }^{7}$ Morphological signs of apoptosis in the nucleus are chromatin condensation and nuclear fragmentation. These signs are disclosed by gathering together of the cell, decrease in cell volume (pyknosis) and retraction of pseudo-pods like blebs. Chromatin condensation begins at the outskirts of the nuclear membrane, forming a bow or ring-like structure. A characteristic feature express as karyorrhexis, is a consolidated chromatin wherein chromatin is condensed until it separates inside a cell with an intact membrane. The plasma membrane is flawless in overall proceeding. At the later phase of apoptosis a some of the morphological features expressed and observed including membrane blabbing, ultra-structural alteration of cytoplasmic organelles and disintegrated cell membrane. ${ }^{8}$ These all features expressed in Figure 1, as schematic presentation and possible inter-relationships between the various cell types observed in the buccal cytome assay based on the scheme proposed by Tolbert et al. ${ }^{9}$

Deformities in DNA repair or chromosomal separation regularly triggers cell death as a safeguard system. Defect in such self-destruction event permits survival of genetically unstable cells which at last advances into tumourigenesis. ${ }^{9}$ This apoptosis defects additionally progress into the metastasis as this imperfection permit epithelial cells to get by in a suspended state, without extracellular matrix cohesion. ${ }^{10}$

Thus, our study aimed to assess chromosomal damage and apoptosis in exfoliated cells collected from the surface of the lesional tissue in patients with OSCC and from buccal mucosa of control subjects using Feulgen reaction and 4', 6Diamidino-2-Phenylindole as fluorescent marker

\section{METHODS}

The present case control study was conducted in the Department of Oral Pathology and Microbiology of the institution from March 2013 to March 2014. Ethical clearance was taken from the institute before commencing the study. As per number of oral cancer patients visited to the hospital previous year, our study constituted total 60 patients; consisting group (a) of 20 patients with clinically suspected lesions of OSCC, excluding patients undergoing chemotherapy and radiotherapy and Group (b) of 20 patients without oral lesions but having history of tobacco consumption in any forms. Control group constituted 20 individuals without history of tobacco consumption in any form. Selection of patients was done randomly from amongst those attending OPD of the institution. After taking informed written consent, detailed case history and clinical examination was done. Examination of the oral cavity was carried out under adequate illumination with the help of tongue depressor, mouth mirror and gauze sponge. Any changes in colour, texture of the mucous membrane, inflammatory areas, indurations and ulcerative growth in the oral mucosa were identified.

The lesional tissue of study group "a", buccal mucosa of study group " $b$ " and control group was selected for acquiring two cytological smears. Before taking the sample, patient was asked to rinse his / her mouth with water. Smears were obtained with the help of cytobrush. The entire selected site was scraped and transferred to a clean glass slide and spread cautiously to avoid overlapping of cells. The smears were then immediately fixed with Clarke's fluid for 16 - 18 minutes. After fixation, one smear was stained with Feulgen reaction and the other with DAPI fluorescent stain.

\section{Feulgen Staining Protocol11}

Solution used for Feulgen staining

1. Schiff's Reagent (100 mL Yucca Diagnostics. YD092).

2. $1 \mathrm{~N}$ Hydrochloric acid Conc. $\mathrm{HCl} 36 \%$ and $11.65 \mathrm{M}$ used to prepare $1 \mathrm{~N} \mathrm{HCL}$ (about $85.8 \mathrm{~mL}$ Conc. $\mathrm{HCl}$ was added to make 1 litre solution of $1 \mathrm{~N}$ ).

3. Distilled Water.

4. Counter stain Orange G (Yucca Diagnostics).

5. DPX mounting media. 


\section{Feulgen Staining Procedure 11}

Each slide was stained according to following steps

- Rinse briefly with water.

- Rinse quickly with cold $1 \mathrm{~N}$ hydrochloric acid.

- $\quad$ Place into prewarmed hydrochloric acid for the proper time at $60^{\circ} \mathrm{C}$ (duration of hydrolysis will rely upon fixative. For example 16 - 18 minutes for Clarke's liquid).

- $\quad$ Rinse quickly with cold $1 \mathrm{~N}$ hydrochloric acid.

- Rinse thoroughly with distilled water.

- Place into Schiff's reagent for 30 an hour at room temperature.

- Wash well with water.

- Counterstain with Orange G for 45 seconds.

- Dehydrate with ethanol clear with xylene and mount with a resin medium.

\section{DAPI Staining Protocol11}

Solutions used for DAPI Staining:

1. DAPI dihydrochloride [(MW 350.3) Invitrogen, Life technologies].

2. Phosphate cushion saline ( $\mathrm{Ph} 7.4)$.

3. Deionized water $(\mathrm{dH} 20)$.

4. DPX. stain and reagent arrangement.

\section{Preparation of the DAPI Stock Solution and Working Solution}

To make a $5 \mathrm{mg} / \mathrm{mL}$ DAPI stock solution (14.3 $\mathrm{mM}$ for the dihydrochloride), break down the substance of one vial (10 $\mathrm{mg}$ ) in $2 \mathrm{~mL}$ of deionized water ( $\mathrm{dH} 2 \mathrm{O})$. To prepare working DAPI solution, dilute the DAPI stock solution for $300 \mathrm{nM}$ in PBS.

\section{DAPI Staining Procedure11}

- Equilibrate the example quickly with phosphatesupported saline (PBS).

- Dilute the DAPI stock solution for $300 \mathrm{nM}$ in PBS. Include around $300 \mu \mathrm{L}$ of this diluted DAPI staining solution.

- The coverslip preparation, verifying that the cells are completely covered.

- Incubate for 1 - 5 minutes.

- Rinse the sample a few times in PBS.

- Drain excess buffer from the coverslip.

- Mount with DPX.

- View the sample utilizing a fluorescence microscope (Motic BA400) with DAPI filters.

\section{Cytological Analysis}

- The slides were investigated at $1000 \mathrm{X}$ magnification utilizing brilliant field and fluorescent microscope.

- $\quad$ Each sample was investigated for number of micronuclei and highlights reminiscent of apoptosis.

\section{Statistical Analysis}

All calculations were performed using Microsoft Excel 2007. The data obtained and expressed as means with standard deviation. It was statistically analyzed with the help of Kruskal Wallis ANOVA, Mann-Whitney U tests. Chi-square test was used for correlation data. Data was analyzed using Statistical Package for Social Sciences (SPSS) version 16.0.

\section{RESULTS}

Apoptosis Analysis Using Feulgen Staining Frequency of apoptosis was found to be 207 in control group, 146 in study group (b) and 120 in study group (a) (OSCC) [Table 1]. Mean frequency of apoptosis varied from 10.4 in control group to 7.3 in study group (b) and 6 in study group (a) (OSCC). It was found to be significantly decreasing from control group to study group (b) to study group (a) (OSCC) and this difference is highly significant statistically $(\mathrm{p}=0.00001)$ [Table 2]. Mean frequency of karyorrhexis varied from $4 \pm 1.2$ in control group to $2.8 \pm 0.8$ in study group (b) and $2.3 \pm 0.6$ in study group (a) (OSCC). It was found to be significantly decreasing from control group to study group (b) to study group (a) (OSCC) and this difference is highly significant statistically $(p=0.00001)$ [Table 2]. Mean frequency of condensed chromosome varied from $5.2 \pm 0.9$ in control group to $3.3 \pm 0.7$ in study group (b) and $2.4 \pm 0.6$ in study group (a) (OSCC). It was found to be significantly decreasing from control group to study group (b) to study group (a) (OSCC) and this difference is highly significant statistically $(p=0.00001)$ [Table 2]. Mean frequency of pyknosis varied from $1.2 \pm 0.6$ in control group to $1.3 \pm 0.7$ in study group (b) and $1.4 \pm 1.0$ in study group (a) (OSCC). It was found to be increasing from control group to study group (b) to study group (a) (OSCC) but this difference is not significant statistically $(p=0.6202)$ [Table 2].

\section{Apoptosis Analysis Using Fluorescent DAPI Staining}

Frequency of apoptosis was found to be 220 in control group, 150 in study group (b) and 130 in study group (a) (OSCC) [Table 1]. Mean Frequency of apoptosis varied from $11 \pm 1.7$ in control group to $7.5 \pm 1.3$ in study group (b) and $6.5 \pm 1.1$ in study group (a) (OSCC). It was found to be significantly decreasing from control group to study group (b) to study group (a) (OSCC) and this difference is highly significant statistically ( $p=0.00001)$ [Table 3].

Mean frequency of karyorrhexis varied from $4.3 \pm 1.1$ in control group to $2.9 \pm 0.7$ in study group (b) and $2.5 \pm 0.5$ in study group (a) (OSCC). It was found to be significantly decreasing from control group to study group (b) to study group (a) (OSCC) and this difference is highly significant statistically ( $p=0.00001)$ [Table 3]. Mean frequency of condensed chromosome varied from $5.4 \pm 0.9$ in control group to $3.3 \pm 0.6$ in study group (b) and $2.6 \pm 0.8$ in study group (a) (OSCC). It was found to be significantly decreasing from control group to study group (b) to study group (a) (OSCC) and this difference is highly significant statistically $(p=0.00001)$ [Table 3].

Mean frequency of pyknosis varied from $1.3 \pm 0.6$ in control group to $1.4 \pm 0.7$ in study group (b) and $1.5 \pm 0.6$ in study group (a) (OSCC). It was found to be significantly increasing from control group to study group (b) to study group (a) (OSCC) but this difference is not significant statistically $(\mathrm{p}=0.5135)$ [Table 3 ]. 


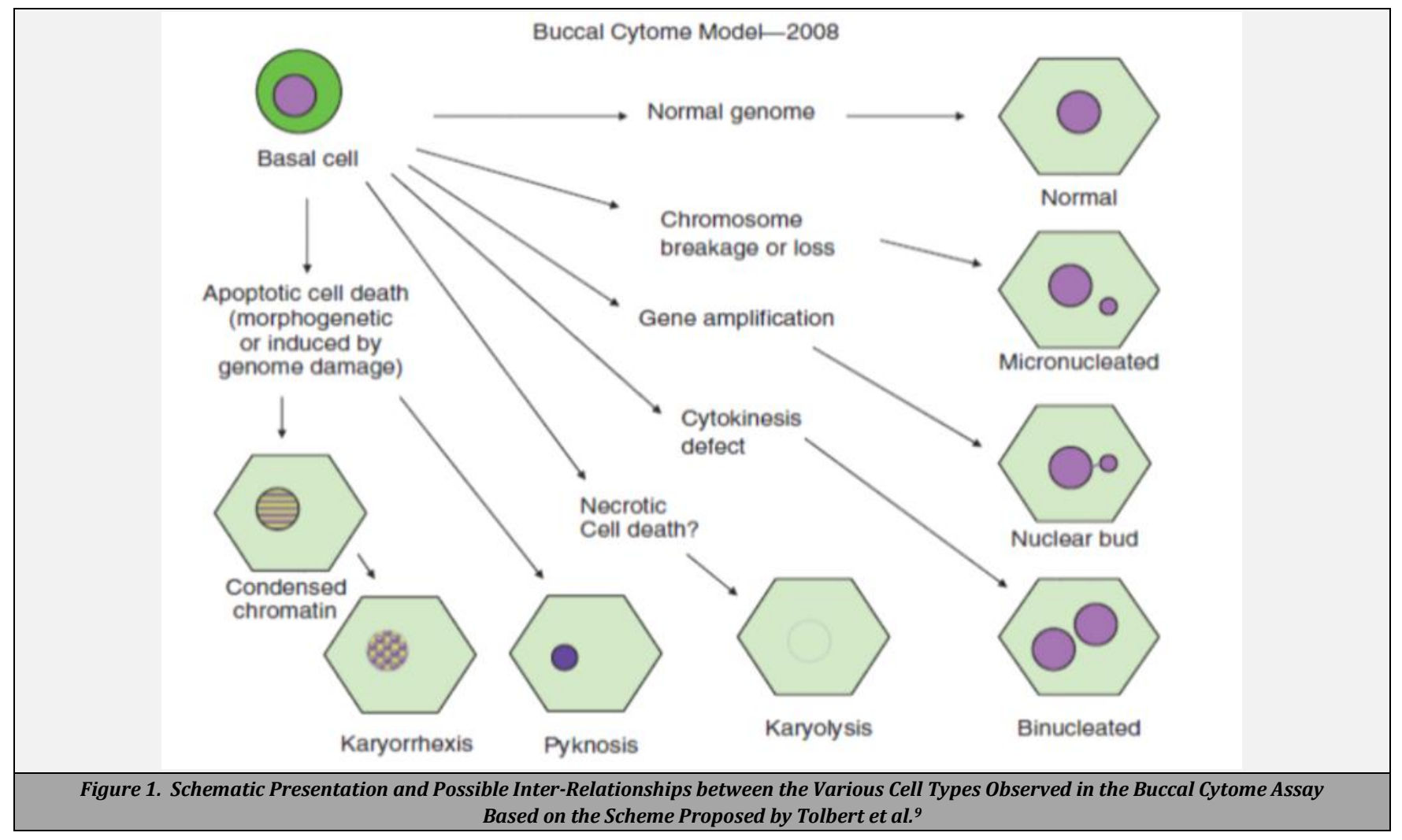

\begin{tabular}{|ccccccc|}
\hline \multicolumn{7}{c|}{ Apoptosis } \\
Groups & Karyorrhexis & Condensed Chromosome & \multicolumn{2}{c|}{ Pyknosis } \\
$(\mathrm{N}=20)$ & Feulgen & DAPI & Feulgen & DAPI & Feulgen & DAPI \\
Study Group (A) & 45 & 49 & 47 & 51 & 28 & 30 \\
Study Group (B) & 55 & 57 & 65 & 65 & 26 & 28 \\
Control Group & 80 & 86 & 104 & 108 & 23 & 26 \\
\hline Table 1. Comparison of Frequency of Apoptosis and Micro Nucleated \\
Cell Count per 100 Cells with Feulgen Reaction and DAPI Staining \\
between Study Group (a), Study Group (b) and Control Group. \\
\hline
\end{tabular}

\begin{tabular}{|c|c|c|c|c|c|c|c|c|}
\hline \multirow{2}{*}{ Groups } & \multicolumn{2}{|c|}{$\begin{array}{l}\text { Condensed } \\
\text { Chromosome }\end{array}$} & \multicolumn{2}{|c|}{$\begin{array}{l}\text { Karyorrhex } \\
\text { is }\end{array}$} & \multicolumn{2}{|c|}{ Pyknosis } & \multicolumn{2}{|c|}{$\begin{array}{c}\text { Total } \\
\text { Apoptosis }\end{array}$} \\
\hline & Mean & SD & Mean & SD & Mean & SD & Mean & SD \\
\hline Control & 5.2 & 0.9 & 4.0 & 1.2 & 1.2 & 0.6 & 10.4 & 1.7 \\
\hline Study Group (b) & 3.3 & 0.7 & 2.8 & 0.8 & 1.3 & & 7.3 & 1.3 \\
\hline Study Gr & 2.4 & & 2.3 & & 1.4 & & & 1.1 \\
\hline & 3.6 & 1. & & & 1.3 & & & 2.3 \\
\hline h-value & \multicolumn{2}{|c|}{43.7725} & \multicolumn{2}{|c|}{25.3050} & \multicolumn{2}{|c|}{0.9555} & \multicolumn{2}{|c|}{38.3967} \\
\hline p-value & \multicolumn{2}{|c|}{$0.00001^{*}$} & \multicolumn{2}{|c|}{$0.00001^{*}$} & \multicolumn{2}{|c|}{0.6202} & \multicolumn{2}{|c|}{$0.00001 *$} \\
\hline \multicolumn{9}{|c|}{ Pair wise Comparison by Mann-Whitney U test } \\
\hline $\begin{array}{l}\text { Control vs. Study } \\
\text { Group (b) }\end{array}$ & \multicolumn{2}{|c|}{$\mathrm{p}=0.00001^{*}$} & \multicolumn{2}{|c|}{$\mathrm{p}=0.0012^{*}$} & \multicolumn{2}{|c|}{$\mathrm{p}=0.4408$} & \multicolumn{2}{|c|}{$\mathrm{p}=0.00001^{*}$} \\
\hline $\begin{array}{l}\text { Control vs. Study } \\
\text { Group (a) }\end{array}$ & \multicolumn{2}{|c|}{$\mathrm{p}=0.00001^{*}$} & \multicolumn{2}{|c|}{$\mathrm{p}=0.00001^{*}$} & \multicolumn{2}{|c|}{$p=0.4408$} & \multicolumn{2}{|c|}{$\mathrm{p}=0.00001^{*}$} \\
\hline $\begin{array}{l}\text { Study Group (b) vs. } \\
\text { Study Group (a) }\end{array}$ & \multicolumn{2}{|c|}{$\mathrm{p}=0.0007^{*}$} & \multicolumn{2}{|c|}{$\mathrm{p}=0.0721$} & \multicolumn{2}{|c|}{$p=0.8287$} & \multicolumn{2}{|c|}{$\mathrm{p}=0.0361^{*}$} \\
\hline \multicolumn{9}{|c|}{$\begin{array}{l}\text { Table 2. Comparison of Mean Number of Karyorrhexis, Condensed } \\
\text { Chromosome, Pyknosis and Total Apoptosis amongst Various Groups } \\
\text { with Feulgen Staining by Kruskal Wallis Anova }\end{array}$} \\
\hline
\end{tabular}

\begin{tabular}{|c|c|c|c|c|c|c|c|c|}
\hline \multirow{2}{*}{ Groups } & \multicolumn{2}{|c|}{$\begin{array}{c}\text { Condensed } \\
\text { Chromosome }\end{array}$} & \multicolumn{2}{|c|}{$\begin{array}{c}\text { Karyorrhex } \\
\text { is }\end{array}$} & \multicolumn{2}{|c|}{ Pyknosis } & \multicolumn{2}{|c|}{$\begin{array}{c}\text { Total } \\
\text { Apoptosis }\end{array}$} \\
\hline & Mean & SD & Mean & SD & Mean & SD & Mean & SD \\
\hline Control & 5.4 & 0.9 & 4.3 & & 1.3 & & & 1.7 \\
\hline Study gro & & 0 & & & & & & 1.3 \\
\hline Study grc & & & & & & & & 1.1 \\
\hline & 3.7 & & & & 1.4 & 0.0 & 8.3 & 2.4 \\
\hline $\mathrm{h}-\mathrm{va}$ & \multicolumn{2}{|c|}{42.3307} & \multicolumn{2}{|c|}{29.6278} & \multicolumn{2}{|c|}{1.3329} & \multicolumn{2}{|c|}{37.8720} \\
\hline & \multicolumn{2}{|c|}{$0.00001^{*}$} & \multicolumn{2}{|c|}{$0.00001 *$} & \multicolumn{2}{|c|}{0.5135} & \multicolumn{2}{|c|}{$0.00001^{*}$} \\
\hline \multicolumn{9}{|c|}{ Pair wise comparison by Mann-Whitney U test } \\
\hline $\begin{array}{l}\text { Control vs. Study } \\
\text { group (b) }\end{array}$ & \multicolumn{2}{|c|}{$\mathrm{p}=0.00001^{*}$} & \multicolumn{2}{|c|}{$\mathrm{p}=0.0001^{*}$} & \multicolumn{2}{|c|}{$\mathrm{p}=0.7251$} & \multicolumn{2}{|c|}{$\mathrm{p}=0.00001^{*}$} \\
\hline $\begin{array}{l}\text { Control vs. Study } \\
\text { group (a) }\end{array}$ & \multicolumn{2}{|c|}{$\mathrm{p}=0.00001^{*}$} & \multicolumn{2}{|c|}{$\mathrm{p}=0.00001^{*}$} & \multicolumn{2}{|c|}{$\mathrm{p}=0.3040$} & \multicolumn{2}{|c|}{$\mathrm{p}=0.00001^{*}$} \\
\hline $\begin{array}{l}\text { Study group (b) vs. } \\
\text { Study group (a) }\end{array}$ & \multicolumn{2}{|c|}{$\mathrm{p}=0.0084^{*}$} & \multicolumn{2}{|c|}{$\mathrm{p}=0.1167$} & \multicolumn{2}{|c|}{$\mathrm{p}=0.5338$} & \multicolumn{2}{|c|}{$\mathrm{p}=0.0361^{*}$} \\
\hline \multicolumn{9}{|c|}{$\begin{array}{c}\text { Table 3. Comparison of Mean Number of Karyorrhexis, Condensed } \\
\text { Chromosome, Pyknosis amongst Various Groups with DAPI Staining } \\
\text { by Kruskal Wallis ANOVA }\end{array}$} \\
\hline
\end{tabular}

\section{DISCUSSION}

Deformities in programmed cell death (apoptosis) is responsible for fundamental act in tumour pathogenesis, allowing neoplastic cells to endure expanded life expectancies.

This ultimately result in tumour mass formation and further progression into metastasis. Lav'inia T'ercia Magalh'aes D' orea et al. ${ }^{1}$ observed that apoptosis occurred significantly less frequently in cells obtained from lesional areas than in cells from the control group ( $p<0.0001)$. Samples from normal areas suggesting that apoptosis is significantly less in case group than control group $(\mathrm{p}<0.0001)$. Throughout quantification done with karyorrhexis, condensed chromatin. It is also found that apoptosis frequency is same between cells from lesional areas and cells from normal areas in the case group ( $\mathrm{p}=0.4786$ ).

Similar results were obtained in our study, in which the frequency of apoptosis (karyorrhexis, condensed chromatin) was found to be significantly decreasing from control group to study group (b) (tobacco chewers) to study group (a) (OSCC) and this difference is highly significant statistically ( $\mathrm{p}=$ $0.00001)$. S. I. Rogovskaya et al. ${ }^{12}$ observed lower frequency of apoptosis in both the lesional and the normal areas in the cancer group. This ultimately suggests that as lesion progress into malignancy, apoptotic response diminished in precursor lesions of cervical cancer.

J. W. Levinson et al. ${ }^{13}$ studied fluorescent Feulgen assay and suggested that acriflavine-Feulgen reaction is a highly appreciated staining method for the quantitative determination of DNA by scanning. The specificity of the method is based on the binding of acriflavine by a Schiff's base to apurinic acid (APA) formed from DNA by acid hydrolysis.

Shaik Begum Khalida also observed a gradual decrease in apoptosis from normal mucosa to precancerous lesions to carcinoma. $(p=0.00001) .{ }^{14}$ 
Amongst all the modalities of performing exfoliative cytology we propose that brush cytology is reliable, harvests more number of cells and can be easily performed with less cost and discomfort to the patient. Various stains have been use to study chromosomal damage and apoptosis in exfoliated cells. We found fluorescent DAPI to be sensitive over Feulgen staining as it limits the incidence of false positives thereby giving more precise evaluation of DNA damage events.

\section{CONCLUSIONS}

Oral cancer is associated with an upsurge in chromosomal damage and impaired apoptosis. Degenerative nuclear alteration indicative of apoptosis can be a useful tool for biomonitoring oral cancer patients. Chromosomal assessment using fluorescent DAPI is cost effective and perhaps the best approach for the screening of OSCC. Use of fluorescent micronucleus assay ensures a key role in the early evaluation of genotoxic damage and primary prevention in the future, which will help in survival to a greater extent and also will reduce the morbidity.

Data sharing statement provided by the authors is available with the full text of this article at jemds.com.

Financial or other competing interests: None.

Disclosure forms provided by the authors are available with the full text of this article at jemds.com.

\section{REFERENCES}

[1] D'orea LTM, Meireles JRC, Lessa JPR, et al. Chromosomal damage and apoptosis in exfoliated buccal cells from individuals with oral cancer. Int J Dent 2012;2012:457054.

[2] Sharma S, Satyanarayana L, Asthana S, et al. Oral cancer statistics in India on the basis of first report of 29 population-based cancer registries. J Oral Maxillofac Pathol 2018;22(1):18-26.

[3] Mehrotra R, Yadav S. Oral squamous cell carcinoma: etiology, pathogenesis and prognostic value of genomic alterations. Indian J Cancer 2006;43(2):60-6.

[4] Fulda S. Tumour resistance to apoptosis. Int J Cancer 2009;124(3):511-5.

[5] Neville BW, Day TA. Oral cancer and precancerous lesions. CA Cancer J Clin 2002;52(4):195-215.

[6] Warnakulasuriya S, Sutherland G, Scully C. Tobacco, oral cancer and treatment of dependence. Oral Oncol 2005;41(3):244-60.

[7] Cooke MS, Evans MD, Dizdaroglu M, et al. Oxidative DNA damage: mechanisms, mutation and disease. FASEB J 2003;17(10):1195-214.

[8] Hassan M, Watari H, AbuAlmaaty A, et al. Apoptosis and molecular targeting therapy in cancer. Article ID 150845, Biomed Res Int 2014;2014:23.

[9] Thomas P, Holland N, Bolognesi C, et al. Buccal micronucleus cytome assay. Nat Protoc 2009;4(6):82537.

[10] Frisch SM, Screaton RA. Anoikis mechanisms. Curr Opin Cell Biol 2001;13(5):555-62.

[11] Pearse AGE. Histochemistry: theoretical and applied. $3^{\text {rd }}$ edn. Edinburgh, London, UK: Churchill Livingstone 1968, 1972.

[12] Rogovskaya SI, Sukhikh GT, Zhdanov AV, et al. Apoptosis in woman uterine cervix in pathologies associated with human papillomavirus. Bull Exp Biol Med 2001;131:57682.

[13] Levinson JW, Langlois RG, Maher VM, et al. An improved acriflavine - Feulgen reagent for quantitative DNA cytofluorometry. J Histochem Cytochem 1978;26(8):6804.

[14] Khalida SB, Manjunath M, Biswas S. Assessment of chromosomal damage and apoptosis in exfoliated buccal cells of potentially malignant disorders and oral cancer. I Dent Otolaryngol 2016;(2):1-4. 